\title{
Resin Composite Materials for Chairside CAD/CAM Restorations: A Comparison of Selected Mechanical Properties
}

\author{
Wojciech Grzebieluch $\left(\mathbb{D},{ }^{1}\right.$ Marcin Mikulewicz $(\mathbb{D}){ }^{2}$ and Urszula Kaczmarek ${ }^{3}{ }^{3}$ \\ ${ }^{1}$ Laboratory for Digital Dentistry, Department of Conservative Dentistry witch Endodontics, Wroclaw Medical University, \\ Krakowska 26, Wrocław 50-425, Poland \\ ${ }^{2}$ Department of Dentofacial Orthopeadics and Orthodontics, Division of Facial Abnormalities, Wroclaw Medical University, \\ Krakowska 26, Wrocław 50-425, Poland \\ ${ }^{3}$ Department of Conservative Dentistry witch Endodontics, Wroclaw Medical University, Krakowska 26, \\ Wrocław 50-425, Poland \\ Correspondence should be addressed to Wojciech Grzebieluch; dentysta@poczta.fm
}

Received 20 April 2020; Revised 2 May 2020; Accepted 16 April 2021; Published 28 April 2021

Academic Editor: Jacek Piskorowski

Copyright (C) 2021 Wojciech Grzebieluch et al. This is an open access article distributed under the Creative Commons Attribution License, which permits unrestricted use, distribution, and reproduction in any medium, provided the original work is properly cited.

\begin{abstract}
Objective. The aim was to evaluate the flexural strength, flexural modulus, microhardness, Weibull modulus, and characteristic strength of six resin composite blocks (Grandio Blocs-GR, Tetric CAD-TE, Brilliant Crios-CR, Katana Avencia-AV, CerasmartCS, and Shofu Block HC-HC). Methods. Flexural strength and flexural modulus were measured using a three-point bending test and microhardness using the Vickers method. Weibull analysis was also performed. Results. The materials showed flexural strength ranging from 120.38 (HC) to $186.02 \mathrm{MPa}(\mathrm{GR})$, flexural modulus from 8.26 (HC) to $16.95 \mathrm{GPa}(\mathrm{GR})$, and microhardness from 70.85 (AV) to 140.43 (GR). Weibull modulus and characteristic strength ranged from 16.35 (CS) to 34.98 (TE) and from 123.45 MPa (HC) to 190.3 MPa (GR), respectively. Conclusions. GR, TE, and CR presented significantly higher flexural strength, modulus, Weibull modulus, and characteristic strength than the others.
\end{abstract}

\section{Introduction}

During the last years, a significant increase in the use of computer-aided design and computer-aided manufacturing $(\mathrm{CAD} / \mathrm{CAM})$ of indirect dental restorations was noticed [1-3].

It resulted from the progress in intraoral imaging, manufacturing technology, hardware development, software, and monolithic materials referred to as blocks suitable for CAD/CAM transfer. Digital systems provide an opportunity to fabricate esthetic fixed restoration within one visit due to the elimination of a number of steps typical of the traditional technique. The rapid fabrication at the chairside of tooth-colored restorations has been obtained by optical impression-taking, designing, and machining. A wide diversity of materials is used for CAD/CAM restorations. These materials are manufactured with the guarantee of desired chemical and physical properties and have superior mechanical strength compared to their conventionally manufactured equivalents [4].

The CAD/CAM materials can be classified as metal, ceramics, resin (polymethyl methacrylate-PMMA, resin composite, nanoceramics), and polymer-infiltrated-ceramic-network material (PICN) [5]. Two types of materials are used currently for aesthetic chairside indirect restorations: glass ceramics/ceramics and resin composites.

$\mathrm{CAD} / \mathrm{CAM}$ resin composites represent a relatively new group of materials, many of them are relatively new and there is a lack of scientific literature data regarding their mechanical properties. The differences between resin composites and ceramic materials are widely known and resulting from their composition and structure, which influence their mechanical properties. Glass-ceramics/ceramics materials display considerably higher values of the flexural modulus $\left(E_{f}\right)$ and Vickers hardness than resin composites $(\geq 60 \mathrm{GPa},>4 \mathrm{GPa}$ versus 9-20 GPa, $0.4 \mathrm{GPa}$, respectively). Despite such 
significant differences, both types of materials are widely and successfully used in restorative dentistry. Resin composite consists of ceramic powders (or ceramic network) and resins are easier to mill and repair intraorally [6-8].

Available long-term clinical studies have proven the durability of CAD/CAM CEREC ${ }^{\circledR}$ (Sirona Dental, Bensheim, Germany) ceramic restorations with a survival rate of $97 \%$ within 5 years, $95.5 \%$ within 9 years, and $88.7 \%$ within 17 years [9-12]. Unfortunately, due to the relatively short availability on the market, there is no long-term clinical trial on CAD/CAM resin composite blocks. Due to the wide range of composite materials for milling, a prediction of clinical success of the chosen material, in practice, is based mainly on their aesthetic properties and less on the mechanical ones that should be similar to the tooth structure. Most of the data is provided by the manufacturers. However, we can find a significant discrepancy in the results, difficult to be explained only by the methodology differences $[6,13,14]$.

The aim of the study was to compare flexural strength, flexural modulus, hardness, and probability of failure of 6 commercially available resin composite CAD/CAM materials.

\section{Materials and Methods}

2.1. Study Design. The comparison of flexural strength, flexural modulus, microhardness, Weibull modulus, and characteristic strength of six composite materials for chairside CAD/CAM system was conducted. The tested composite CAD/CAM blocks were Grandio blocs ${ }^{\circledR}$ (VOCO, Cuxhaven, Germany), Tetric $\mathrm{CAD}^{\circledR}$ (Ivoclar Vivaden, Schaan, Liechtenstein), Brilliant Crios ${ }^{\circledR}$ (Coltene/Whaledent A.G. Altstatten, Switzerland), Katana Avencia Block ${ }^{\circledR}$ (Kuray Noritake Dental, Tokyo, Japan), Cerasmart ${ }^{\circledR}$ (GC Dental Product Europe, Leuven, Belgium), and Shofu Block $\mathrm{HC}^{\circledR}$ (Shofu Inc., Kyoto, Japan), their composition according to literature is placed in Table 1 [15-20].

2.2. Samples Fabrication. The CAD/CAM blocks were cut with a low speed water-cooled diamond saw Miracut 151 (Metcon, Bursa, Turkey) to obtain sixty bar-shaped specimens, ten for each material. Specimens were finished by a glass grinder (JZO, Jelenia Gora, Poland) with wet silicon carbide (initially 240 ISO/FEPA, average grain size $68 \mu \mathrm{m}$ and finally 400 ISO/FEPA, average grain size $35 \mu \mathrm{m}$ ) until dimensions of $15 \mathrm{~mm}$ long, $4 \mathrm{~mm}$ wide, and $1.5 \mathrm{~mm}$ thick were reached according to ISO 6872:2015 (accuracy $0.01 \mathrm{~mm}$ ) [21]. The samples were stored dry at room temperature. Sample preparation according to ISO 4049 was not possible due to the size of the material blocks [22].

2.3. Methods. Flexural properties were measured using a three-point bending test that was conducted with a support span of $12 \mathrm{~mm}$ and a speed of $1 \mathrm{~mm} / \mathrm{min}$ using a universal testing machine LabTest 5.030S LaborTech ${ }^{\circledR}$ (LaborTech Opava, Czech Republic) equipped with Test\&Motion ${ }^{\circledR}$ (LaborTech Opava, Czech Republic) software (in accordance with the ISO 6872:2015) [21].
The flexural strength $\left(\sigma_{f}\right)$ was calculated from the threepoint bending results using the following formula:

$$
\sigma_{f}=\frac{3 F l}{2 w h^{2}}
$$

where $F$ is the maximum load during the flexural test, $l$ the roller span $(12 \mathrm{~mm}), w$ the width $(4 \mathrm{~mm})$, and $h$ the height $(2 \mathrm{~mm})$ of the bar.

The flexural modulus $\left(E_{f}\right)$ was calculated from the threepoint bending results using the following formula:

$$
E_{f}=\frac{F l^{3}}{4 w h^{3} d},
$$

where $F$ is the load, $l$ the roller span $(12 \mathrm{~mm}), w$ the width ( $4 \mathrm{~mm})$ and $h$ the height $(2 \mathrm{~mm})$ of the bar, $d$ is the deflection corresponding to load $F$.

The microhardness was measured by means of a Vickers intender tester (Shimadzu HMV-2T, Shimadzu Corp. Kyoto, Japan) with a load of $980.7 \mathrm{mN}$ (HV 0.1) and dwell time of 10s. Five indentations were applied in a random location for each specimen. Then, the machine automatically calculated the hardness value as HV 01. Before the measurement, surfaces of the samples were sequentially polished with composite rubbers HiLusterPlus ${ }^{\circledR}$ Polishing System (Kerr Corp., Orange, CA, USA). The microhardness measurements were carried out on the same samples that were used in a three-point bending test.

2.4. Statistical Analysis. The obtained data were tested using one-way ANOVA analysis for homogeneity of variance $(p<0.05)$, following multiple comparisons post hoc Tukey's test using Statistica 13 PL software (StatSoft Poland). The significance level was set at $p \leq 0.05$. Weibull statistics were also carried out to obtain the shape and scale parameters. Weibull modulus $(m)$ and probability of failure $\left(P_{f}\right)$ were calculated using the following equation:

$$
P_{f}=1-\exp \left[-N \cdot\left(\frac{\sigma}{\sigma_{0}}\right)^{m}\right],
$$

where $m$ is Weibull modulus, $\sigma_{0}$ is Weibull characteristic strength, and $\sigma$ is flexural strength.

\section{Results}

Mean flexural strength, flexural modulus, and microhardness for all tested materials are shown in Table 2 and Figures 1-3. A statistically significant difference between means of all studied parameters was found.

The values of flexural strength ranged from 120.38 (SD 6.54) MPa for HC to 186.02 (SD 10.49) MPa for GR. Flexural strength of GR was significantly higher in comparison to the other tested materials $(p<0.001)$ and was also significantly higher for TE and CR compared to AV and CS, and for TE, $\mathrm{CR}, \mathrm{AV}$, and CS compared to HC. No significant differences between the pairs CR-TE and AV-CS were found. Flexural strength ranged in the decreasing order as follows: $\mathrm{GR}>\mathrm{TE}>\mathrm{CR}>\mathrm{AV}>\mathrm{CS}>\mathrm{HC}$. 
TABLE 1: Machinable materials used in the study.

\begin{tabular}{|c|c|c|c|c|c|c|}
\hline Brand & Abr. & Manufacturer & Composition & Lot no. & Shade & $\begin{array}{c}\text { Block } \\
\text { size }\end{array}$ \\
\hline Grandio blocs & GR & $\begin{array}{l}\text { VOCO, Cuxhaven, } \\
\text { Germany }\end{array}$ & 86 wt $\%$ nanohybride fillers, $14 \%$ UDMA + DMA $[15,16]$ & 1711521 & A2 HT & C $14 \mathrm{~L}$ \\
\hline Tetric CAD & $\mathrm{TE}$ & $\begin{array}{l}\text { Ivoclar vivaden, Schaan, } \\
\text { Liechtenstein }\end{array}$ & $\begin{array}{c}\text { Dimethacrylates } 28.4 \mathrm{wt} \% \text { : Bis-GMA, Bis-EMA, TEGDMA, } \\
\text { UDMA; fillers: } 71,1 \mathrm{wt} \% \text {, barium glass }(<1 \mathrm{um}) \text {, silicon } \\
\text { dioxide }(<20 \mathrm{~nm})[17]\end{array}$ & 35470 & $\begin{array}{l}3 \mathrm{M} 2 \\
\mathrm{HT}\end{array}$ & 14 \\
\hline Brilliant crios & CR & $\begin{array}{l}\text { Coltene/Whaledent A.G. } \\
\text { Altstatten, Switzerland }\end{array}$ & $\begin{array}{l}\text { Resin matrix cross-linked methacrylate, } 70.7 \mathrm{wt} \% \text { barium } \\
\text { glass }(<1 \mu \mathrm{m}) \text {, amorphous silica }(<20 \mathrm{~nm})[15,18]\end{array}$ & H22667 & A2 LT & C 14 \\
\hline $\begin{array}{l}\text { Katana } \\
\text { avencia block }\end{array}$ & AV & $\begin{array}{l}\text { Kuray Noritake dental, } \\
\text { Tokyo, Japan }\end{array}$ & $\begin{array}{l}\text { UDMA, TEGDMA with } 62 \mathrm{wt} \% \text { aluminum filler }(20 \mathrm{~nm}) \text {, } \\
\text { silica filler }(40 \mathrm{~nm})[19]\end{array}$ & 000318 & A2LT & 12 \\
\hline Cerasmart & CS & $\begin{array}{l}\text { GC dental product } \\
\text { Europe, Leuven, Belgium }\end{array}$ & $\begin{array}{c}\text { BisMEPP, UDMA, DMA with } 71 \% \text { wt } \% \text { silica }(20 \mathrm{~nm}) \text { and } \\
\text { barium glass }(300 \mathrm{~nm})[15,19]\end{array}$ & 37690 & A3 C & 14 \\
\hline $\begin{array}{l}\text { Shofu block } \\
\text { HC }\end{array}$ & $\mathrm{HC}$ & Shofu inc., Kyoto, Japan & $\begin{array}{c}\text { UDMA, TEGMA, } 61 \text { wt } \% \text { silica powder, micro fumed silica, } \\
\text { zirconium silicate }[15,19]\end{array}$ & 071601 & A2 LT & 14 \\
\hline
\end{tabular}

UMDA: urethane dimethacrylate; TEGDMA: triethylene glycol dimethacrylate; Bis-GMA: bisphenol A diglycidylether methacrylate; Bis-EMA: ethoxylate bisphenol-A dimethacrylate; DMA: dimethacrylate; Bis-MEEP: 2,2-Bis(4-methacryloxypolyethoxyphenyl) propane; EDMA: ethyleneglycoldimethacrylate; DMA: dimethacrylate.

TABLE 2: Mechanical properties of the testing materials.

\begin{tabular}{|c|c|c|c|c|c|}
\hline Material & $\begin{array}{c}\sigma_{f}(\mathrm{MPa}) \\
\bar{x}(\mathrm{SD})\end{array}$ & $\begin{array}{c}E_{f}(\mathrm{GPa}) \\
\frac{x}{(\mathrm{SD})}\end{array}$ & $\begin{array}{l}\text { HV01 } \\
\bar{x}(\mathrm{SD}) \\
\end{array}$ & $m$ & $\sigma_{0}(\mathrm{MPa})$ \\
\hline$\overline{G R}$ & $186.02(10.49) \mathrm{A}$ & $16.95(0.50) \mathrm{A}$ & $140.43(5.47) \mathrm{A}$ & 25.72 & 190.30 \\
\hline $\mathrm{TE}$ & $170.65(5.61) \mathrm{B}$ & $10.56(0.19) \mathrm{B}$ & 74.88 (2.82) BC & 34.89 & 173.26 \\
\hline CR & $170.46(8.89) \mathrm{B}$ & $11.14(0.16) \mathrm{C}$ & $75.40(2.18) \mathrm{B}$ & 27.18 & 174.16 \\
\hline $\mathrm{AV}$ & $142.79(6.56) \mathrm{C}$ & $8.39(0.13) \mathrm{D}$ & 70.85 (1.62) C & 22.92 & 145.90 \\
\hline CS & $136.27(9.40) \mathrm{C}$ & $8.45(0.20) \mathrm{D}$ & $71.13(0.92) \mathrm{BC}$ & 16.35 & 140.50 \\
\hline $\mathrm{HC}$ & $120.38(6.54) \mathrm{D}$ & $8.26(0.55) \mathrm{D}$ & 77.84 (5.11) B & 19.62 & 123.45 \\
\hline$p$ value ${ }^{*}$ & $\mathbf{p}<0.001$ & $\mathbf{p}<0.001$ & $\mathbf{p}<0.001$ & - & - \\
\hline
\end{tabular}

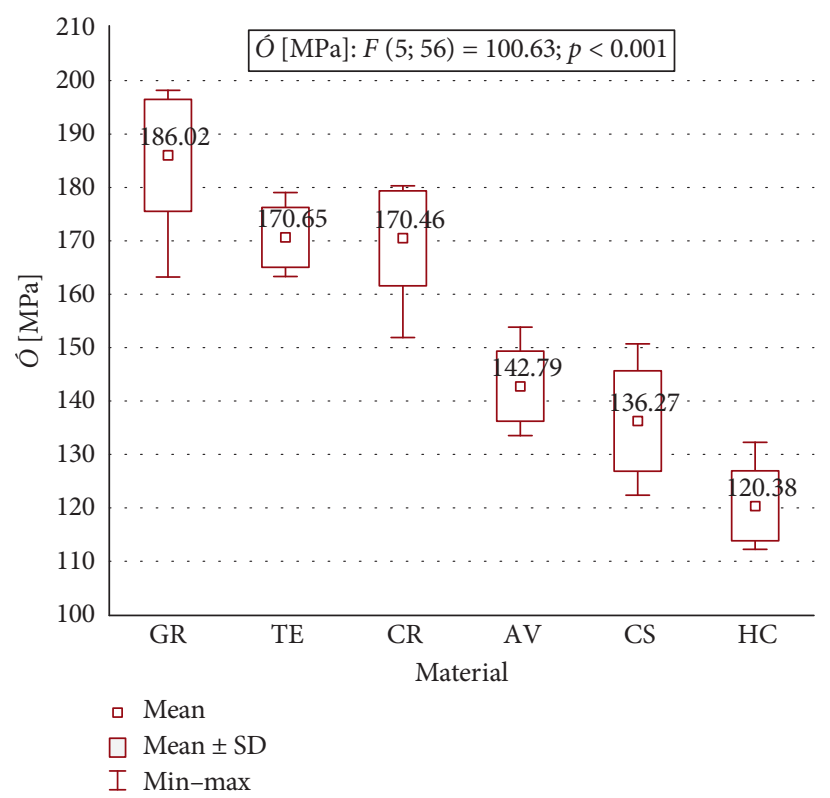

Figure 1: Flexural strength of the testing materials.

The flexural modulus values ranged from 8.26 (SD 0.55) GPa for HC to 16.95 (SD 0.50) GPa for GR. The flexural modulus of GR was significantly higher in comparison to the other tested materials and was also higher for TE and CR compared to AV, CS and HC. The values of flexural modulus changed in the descending order as follows: GR $>\mathrm{CR}>$ $\mathrm{TE}>\mathrm{CS}>\mathrm{AV}>\mathrm{HC}$.

The values of microhardness ranged from 70.85 (SD 1.62) for $\mathrm{AV}$ to 140.43 (SD 5.47) for GR. The microhardness of GR was significantly higher compared to the other tested 


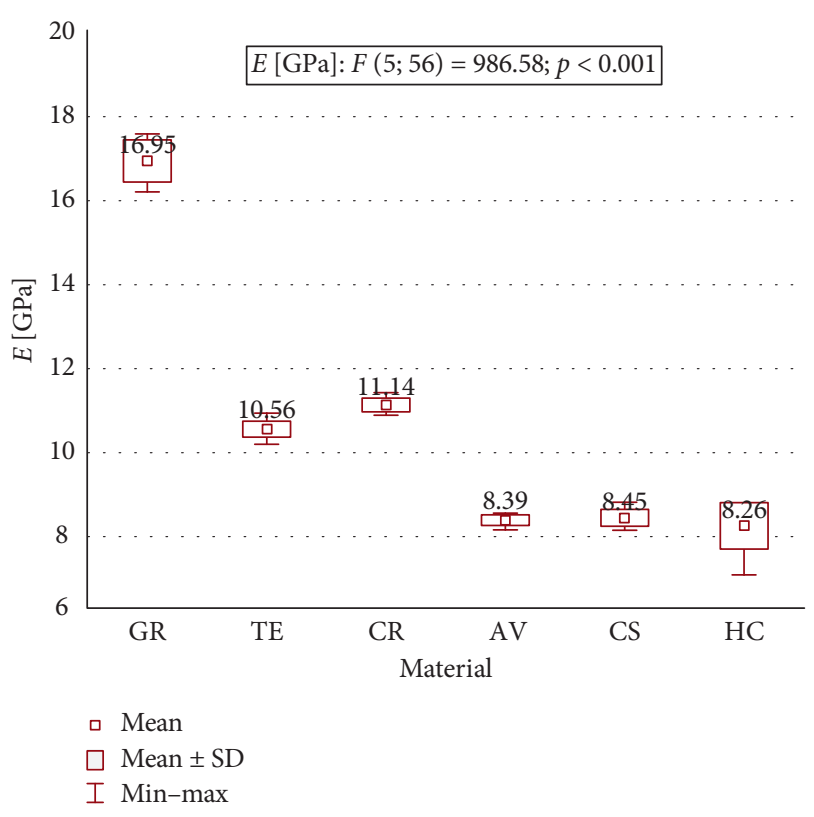

FIgURE 2: Flexural modulus of the testing materials.

materials. Similar values for TE and CS as well as for CR and $\mathrm{HC}$ were found. The microhardness values in the diminishing order were as follows: $\mathrm{GR}>\mathrm{HC}>\mathrm{CR}>\mathrm{TE}>\mathrm{CS}>\mathrm{AV}$.

Calculated Weibull modulus $(m)$ ranged from 16.35 for CS to 34.89 for TE. The ranking of the Weibull modulus was as follows $\mathrm{CS}>\mathrm{HC}>\mathrm{AV}>\mathrm{GR}>\mathrm{CR}>\mathrm{TE}$. Weibull survival curves of the flexural strength, showing a probability of failure $\left(P_{f}\right)$ at any stress level, are shown in Figure 4. Weibull characteristic strength $\left(\sigma_{0}\right)$ ranged from 123.45 for $\mathrm{HC}$ to 190.30 for GR (Table 2). The values of Weibull characteristic strength $\left(\sigma_{0}\right)$ in the diminishing order were as follows: $\mathrm{GR}>\mathrm{CR}>\mathrm{TE}>\mathrm{AV}>\mathrm{CS}>\mathrm{HC}$.

\section{Discussion}

Mechanical properties of dental materials are assessed based on the results of in vitro testing. The characteristics of dental materials in laboratory conditions can predict clinical performance to some extent although an imitation of an oral environment is difficult to be reconstructed in vitro. International Standard Organization elaborated protocols, standardized testing methods, and the required qualities allow for comparisons of dental restorative material properties. The test results performed according to the standard procedures can eliminate the unfounded claims of manufacturers regarding material superiority and predict the success of the dental material in clinical conditions [23].

Dental restorative materials, besides fulfillment of the aesthetic demands, ought to withstand the biomechanical forces placed upon them during function. Because dental restorations are static entities, all mechanical properties of the restorative materials are measured regarding their resistance to deformation or fracture under the applied load [23].

The forces acting upon material are mainly tensile, compressive, shearing, and torsional. Additionally, bending forces being a compilation of tension, compression, and

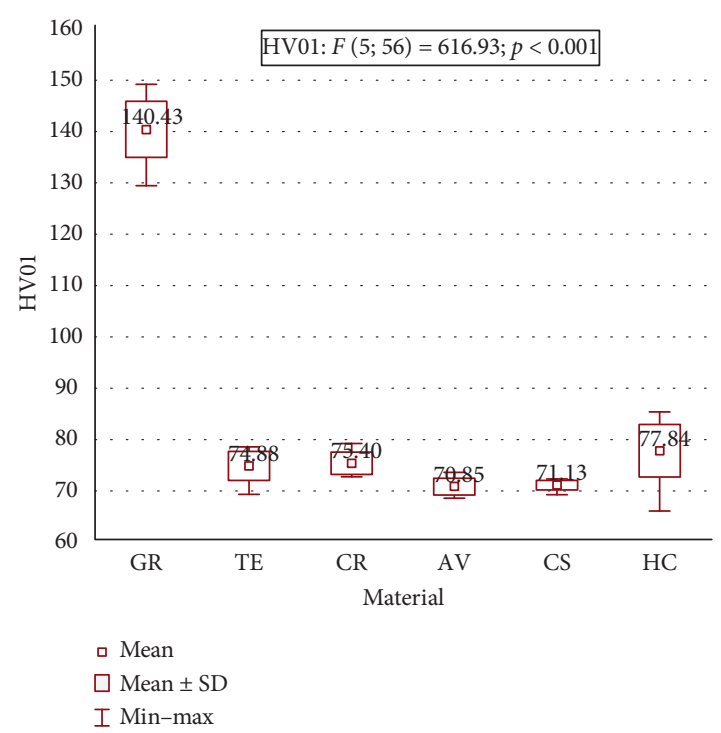

FIGURE 3: Microhardness of the testing materials.

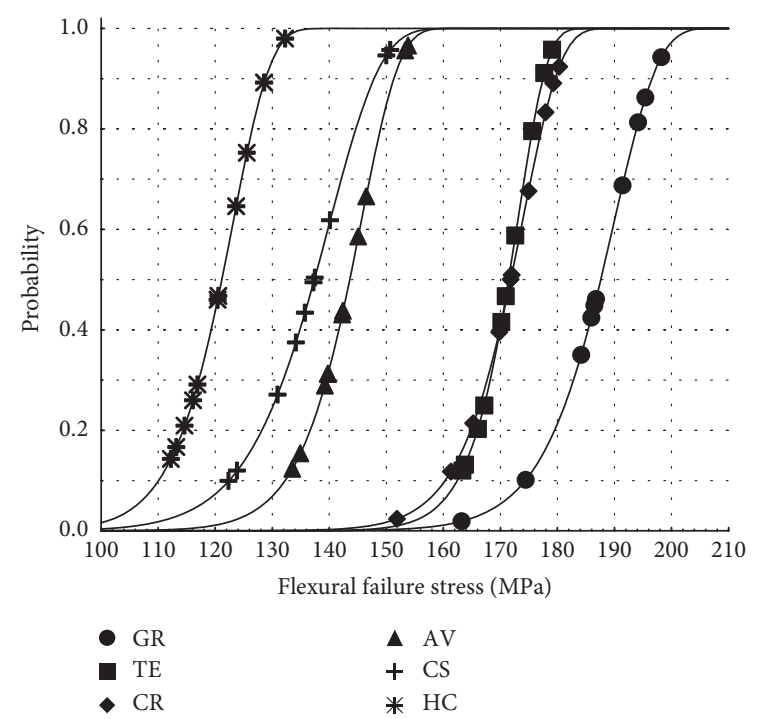

FIgURE 4: Weibull survival curves of the flexural strength of the testing materials.

shear forces are subjected intraorally. Despite the common failure of dental materials caused by tensile stress, any force applied to a restoration is probably a combination of tensile, compressive, and shear forces. Consequently, flexural strength, tested with the use of a three-point bending test, reflects compressive and shear stresses in the same sample, and it is the best way to mimic stresses which are applied on the dental materials in oral condition [24-26].

The flexural strength presents the greatest stress experienced by the material at the time of failure. Therefore, a high value of $\sigma_{f}$ is a required property for the indirect restoration materials to withstand the forces of mastication without fracture.

The tested materials are designed for permanent indirect single-tooth restorations such as inlays/onlays, veneers, partial crowns, or full crowns. Therefore, they should have mechanical properties resembling those of hard dental 
tissues. In our study, the measured flexural strength after dry storage of the samples differed from 120.38 to $186.02 \mathrm{MPa}$ (about 65\%). However, the obtained values were comparable with those of the dentine, which varied from $109 \pm 10$ to $212.9 \pm 41.9 \mathrm{MPa}[27,28]$. Of the studied CAD/CAM materials, GR, being the most filled composite material in this comparison, revealed the highest value of flexural strength compared to other materials. However, it was much lower than the biaxial flexural strength given by the manufacturer (186.02 MPa vs. $333 \mathrm{MPa}$, respectively) [16]. The difference seems to be too large to be explained by the use of a different measurement method [29]. TE and CR revealed slightly lower strength, around $170 \mathrm{MPa}$. TE showed much lower than the biaxial flexural strength given by the manufacturer (170.65 MPa vs. 273.79 MPa, respectively) [17]. CR had some lower flexural strength in comparison to the one found in the literature recorded after $24 \mathrm{~h}$ water storage (170.46 vs. $198 \mathrm{MPa}$ ) [30]. CS turned out also to have a lower value of flexural strength than the manufacturer's data and the results of other studies, regardless of the material storage $[20,25,31-34]$. Similarly, HC revealed lower flexural strength than the manufacturer's data and the results of other studies obtained after dry storage and similar to data obtained after thermocycling and water storage [20,30]. GR, TE, and CR presented significantly higher flexural strength than the other materials, whereas the CS, having a similar filler content to TE and CR, showed significantly lower strength. The recorded flexural strength values, lower than those reported by other authors and manufacturers, may be the result of the difference in applied methodology (e.g., the roughness of the sample surface, the roller span, and geometry of the samples) and also the material manufacturing process deviations $[20,25,30,31,33,34]$.

The flexural strength is the important parameter that determines the material properties but does not determine how the material will be deformed during loading. Therefore, for a better understanding of material behavior, it is necessary to determine elastic properties by measuring the flexural modulus. The 3-point bend test allows calculating simultaneously the flexural strength and the flexural modulus $E_{f}$. The flexural modulus is called "modulus of elasticity in bending," or "modulus of elasticity" or "elastic modulus," or simply "modulus" is represented by the slope of the stressstrain curve obtained during the first or initial step of the 3point bend test and determines the stiffness $[21,25,26]$.

$E$ moduli of the dental hard tissues based on the literature range from 74 to $130 \mathrm{GPa}$ for the human enamel and from 17.7 to $29.8 \mathrm{GPa}$ for the dentine [35-38]. Comparison of these parameters reveals a significant difference between enamel and dentine. Mechanical properties of the tissues, including $E$ modulus, change within a tooth structure depending on the location and depend on many factors, e.g., mineralization, tubule density, and orientation [35, 39].

The obtained results showed that the tested materials, stored in dry conditions, presented much smaller values of elastic modulus compared to the enamel. Only one of the tested materials-GR revealed the flexural modulus value close to the dentine ones. The GR flexural modulus was highest and nearly 2 -fold higher than the values recorded for
$\mathrm{AV}, \mathrm{CS}$ and HC. CR and TE presented lower flexural modulus than GR, but significantly higher compared to the values recorded for $\mathrm{AV}, \mathrm{CS}$, and $\mathrm{HC}$. The flexural modulus values recorded for $\mathrm{GR}, \mathrm{CR}$, and $\mathrm{HC}$ were similar to values obtained in different research papers $[18,20,25,30]$. The HC revealed a lower value of flexural modulus than the one given by Lauvahutaton et al. in dry conditions [20]. The CS flexural modulus value obtained in this study was lower compared to the study by Lauvahutaton et al. [20] and Lawson et al. [32] and higher than reported by Awada and Nathanson [25].

Resin composites tested in this study are made of resin bonded filler which results in much lower $E$ module values than those of enamel. It is worth mentioning, a new type of material-polymer infiltrated ceramic-network (PICN) is manufactured not by polymerization of the resin mixed with powder but by resin infiltration of a porous sintered solid ceramic block. As a result of this process, a composite with $E$ modulus of 27.26 to $37.95 \mathrm{GPa}$ is obtained [5, 40, 41]. However, this material has lower flexural strength values than most CAD/CAM resin composites reviewed in this study. It exceeds only the flexural strength of HC [42].

Materials with low $E$ modulus values transfer more loads inside the tooth structures than stiffer ceramic materials [43]. Despite them, the clinical results of resin composites do not differ from gold cast restorations [44].

The surface hardness of a dental material can be considered as a predictor of the wear resistance of a material $[35,45]$. However, the lower hardness of the CAD/CAM materials contributes to their milling susceptibility [6].

Microhardness testing (Vickers) revealed that GR, containing $86 \%$ filler by weight, was the hardest among the studied CAD/CAM materials, nearly 2 -fold harder than the others. The obtained result was slightly lower compared to the manufacturer's data [16] (140.43 vs. 154.6) and higher compared to the data obtained by Alamoush et al. [15], (140.43 vs. 121.8). Similarly, CS microhardness was higher compared to Lauvahutaton et al. [20], Lawson et al. [32], and Kamonwanon et al. [46]. Microhardness values for $\mathrm{HC}$ were higher than the value contained in the independent data and that of the manufacturer's [20, 46]. Kamonwanon et al. [46] found lower hardness value (almost half) for $\mathrm{CS}, \mathrm{AV}$, and $\mathrm{HC}$ than our results and also lower than those obtained by Alamoush et al. [15], Lauvahutaton et al. [20], and Lawson et al. [32]. The enamel hardness ranges from 270 to 360 and the dentine's from 50 to $62.3[15,47]$. Our data showed that the hardness of all the tested materials was higher than the dentine's but much lower than the enamel's one. When comparing the microhardness of the resin composite materials, we should also notice that hardness is not a predictor of material wear. The resin composite material wear will not only be the result of friction but also occurs due to chemical degradation caused by an aggressive oral cavity environment $[48,49]$.

Nowadays, researchers utilize Weibull statistics which is based on "weakest link theory" and allows to estimate the probability of material failure [50-52]. Weibull modulus $(m)$ has an important practical indication because a higher $m$ value means smaller deviations of flexural strength and indicates better homogeneity of the material. For this reason, materials with higher $m$ value are preferable, even in 
association with slightly lower flexural strength [50-52]. Determining the probability of failure at any possible stress level allows to evaluate the reliability of materials and to estimate the dependability of the tested materials as a load function [53]. Weibull's characteristic strength value estimates that the probability of failure equals $63.2 \%$ $\left(p_{f}=63.2 \%\right)$. TE showed the highest $m$ value (34.89) at $\sigma_{0}$ of $173.26 \mathrm{MPa}$, while GR, a material with the highest $\sigma_{0}$ of $190.30 \mathrm{MPa}$, showed $m$ value of 25.72. The $m$ and $\sigma_{0}$ values of GR, TE, and CR are higher than recorded for CS (lowest $\mathrm{m}$ ) and HC (lowest $\sigma_{0}$ ). Stawarczyk et al. [34] reported lower Weibull modulus and higher characteristic strength values for CS and HC. The difference may be explained in sample surface roughness. Mentioned above authors polished samples up to P4000 (average grain size $2.5 \mu \mathrm{m}$ ) vs. P400 (present study-average grain size $35 \mu \mathrm{m}$ ). However, it should be remembered that the milling machine processes the material with a diamond drills and the obtained surface is affected by the milling process and rough. [54] During clinical procedure, the internal surface of resin composites is usually sandblasted before adhesive cementation $(50 \mu \mathrm{m}$ $\mathrm{AlO}_{2}$ ) and only the external surface is polished.

\section{Conclusion}

Within the limitation of this in vitro study, it can be concluded that flexural strength, flexural modulus, and Vickers hardness of the tested materials presented significant differences.

Therefore, clinicians are advised to take into consideration these differences when planning teeth indirect restoration using these materials.

GR, TE, and CR presented significantly higher flexural strength, flexural modulus, Weibull modulus, and Weibull characteristic strength than the others.

There is a need to develop restoration materials (method) in terms of stress-strain behavior more similar to the natural tooth structure. $\sigma_{f}$. flexural strength; $E_{f}$. flexural modulus; HV01: Vickers microhardness; $m$ : Weibull modulus; and $\sigma_{0}$ : Weibull characteristic strength. Materials with the same letter within a column are not significantly different $(p>0.05)$. Mean values $(n=10)$ and standard deviations in parentheses. $\bar{x}$ : mean; SD: standard deviation.

\section{Data Availability}

Data are available upon request.

\section{Conflicts of Interest}

The authors declare that they have no conflicts of interest.

\section{Acknowledgments}

The research was supported by Medical University of Wroclaw under grant ST.B010.17.02.

\section{References}

[1] D. J. Poticny and J. Klim, "CAD/CAM in-office technology: innovations after 25 years for predictable, esthetic outcomes,"
The Journal of the American Dental Association, vol. 141, pp. 5S-9S, 2010.

[2] D. J. Fasbinder, "Chairside CAD/CAM: an overview of restorative material options," Compendium Continuing Education Dentistry, vol. 33, no. 1, pp. 52-58, 2012.

[3] F. A. Spitznagel, J. Boldt, and P. C. Gierthmuehlen, "CAD/ CAM ceramic restorative materials for natural teeth," Journal of Dental Research, vol. 97, no. 10, pp. 1082-1091, 2018.

[4] J.-F. Nguyen, V. Migonney, N. D. Ruse, and M. Sadoun, "Resin composite blocks via high-pressure high-temperature polymerization," Dental Materials, vol. 28, no. 5, pp. 529-534, 2012.

[5] H. Lambert, J.-C. Durand, B. Jacquot, and M. Fages, "Dental biomaterials for chairside CAD/CAM: state of the art," The Journal of Advanced Prosthodontics, vol. 9, no. 6, pp. 486-495, 2017.

[6] N. D. Ruse and M. J. Sadoun, "Resin-composite blocks for dental CAD/CAM applications," Journal of Dental Research, vol. 93, no. 12, pp. 1232-1234, 2014.

[7] L.-H. He and M. Swain, "A novel polymer infiltrated ceramic dental material,” Dental Materials, vol. 27, no. 6, pp. 527-534, 2011.

[8] S. D. Horvath, "Key parameters of hybrid materials for CAD/ CAM-Based restorative dentistry," Compendium of Continuing Education in Dentistry (Jamesburg, N.J: 1995), vol. 37 , no. 9, pp. 638-643, 2016.

[9] A. K. Mainjot, N. M. Dupont, J. C. Oudkerk, T. Y. Dewael, and M. J. Sadoun, "From artisanal to CAD-CAM blocks: state of the art of indirect composites from artisanal to CAD-CAM blocks," Journal of Dental Research, vol. 95, no. 5, pp. 487-495, 2016.

[10] R. Hickel and J. Manhart, "Longevity of restorations in posterior teeth and reasons for failure," The Journal of Adhesive Dentistry, vol. 3, no. 1, pp. 45-64, 2001.

[11] T. Otto and D. Schneider, "Long-term clinical ersults of chairside cerec CAD/CAM inlays and onlays: a case series," The International Journal of Prosthodontics, vol. 21, no. 1, pp. 53-59, 2008.

[12] A. Posselt and T. Kerschbaum, "Longevity of 2328 chairside Cerec inlays and onlays," International Journal of Computerized Dentistry, vol. 6, no. 3, pp. 231-248, 2003.

[13] F. Vafaee, F. Firooz, B. Heidari, M. khoshhal, F. Fotovat, and H. Allahbakhshi, "A comparative study of flexural strength and fatigue resistance of 2 nanoceramic composite resin cad/ cam blocks (lava ultimate and vita enamic) and a lithium disilicate glass ceramic (ips E.max cad)," Biomedical and Pharmacology Journal, vol. 10, no. 1, pp. 51-58, 2017.

[14] "Lava ${ }^{\mathrm{TM}}$ ultimate CAD/CAM restorative. dental products, $3 \mathrm{M}$ center building 275-2SE-03 St. paul," 2019, http://www.d-way. cz/data/product/13/23/files/Lava_Ult_TPP.pdf.

[15] R. A. Alamoush, N. Silikas, N. A. Salim, S. Al-Nasreavi, and J. D. Satterthwaite, "Effect of the composition of CAD/CAM composite blocks on mechanical properties," BioMed Research International, vol. 2018, Article ID 4893143, 8 pages, 2018.

[16] "Grandio blocs strongest in its class," 2018, https://cdn. vivarep.com/contrib/va/documents/pdf_125_2_5067_vc8400 6000us_20180319191736431.20180322173746219.pdf.

[17] Ivoclar Vivadent AG Research and Development Scientific Service, Tetric CAD Scientific Documentation, Ivoclar Vivadent AG Research and Development Scientific Service, Schaan, Liechtenstein, 2018, https://www.google.com/url?sa= $\mathrm{t} \& \mathrm{rct}=\mathrm{j} \& \mathrm{q}=\&$ esrc $=\mathrm{s} \&$ source $=$ web \& $\mathrm{cd}=2 \& \mathrm{ved}=2 \mathrm{ahUKEwin} 2$ IbXteHeAhWDMewKHUh6DP4QFjABegQIAxAC\&url=htt ps\%3A\%2F\%2Fwww.ivoclarvivadent.com\%2Fzoolu-website \%2Fmedia\%2Fdocument\%2F44594\%2FTetric\%2BCAD\&usg =AOvVaw1xdegLywj1KTmLllTnLJtV. 
[18] “Brilliant crios product guidline," 2018, https://www.coltene. com/pim/DOC/BRO/docbro60021815-06-16-en-brilliant-cri os-product-guideline-viewsenaindv1.pdf.

[19] H. Koizumi, O. Saiki, H. Nogawa, H. Hiraba, T. Okazaki, and H. Matsumura, "Surface roughness and gloss of current CAD/ CAM resin composites before and after toothbrush abrasion," Dental Materials Journal, vol. 34, no. 6, pp. 881-887, 2015.

[20] S. Lauvahutanon, H. Takahashi, M. Shiozawa et al., "Mechanical properties of composite resin blocks for CAD/CAM," Dental Materials Journal, vol. 33, no. 5, pp. 705-710, 2014.

[21] ISO 6872, Dentistry-Ceramic Materials, International Organization for Standardization, Geneva, Switzerland, 4th edition, 2015.

[22] ISO 4049, Dentistry-Polymer Based Restorative Materials, International Organization for Standardization, Geneva, Switzerland, 4th edition, 2009.

[23] J. J. Anusavice, Phillips' Science of Dental Materials, Elsevier, St Louis, Missouri, 11th edition, 2003.

[24] J. Manhart, K.-H. Kunzelmann, H. Y. Chen, and R. Hickel, "Mechanical properties of new composite restorative materials," Journal of Biomedical Materials Research, vol. 53, no. 4, pp. 353-361, 2000.

[25] A. Awada and D. Nathanson, "Mechanical properties of resinceramic CAD/CAM restorative materials," The Journal of Prosthetic Dentistry, vol. 114, no. 4, pp. 587-593, 2015.

[26] I. Thornton, Mechanical Properties of Dental Resin Composite CAD/CAM Blocks, The University Of British Columbia, Vancouver, Canada, 2014, https://circle.ubc.ca/bitstream/ handle/2429/48603/ubc_2014_september_thornton_ian.pdf? sequence $=1$.

[27] D. D. Arola and R. K. Reprogel, "Tubule orientation and the fatigue strength of human dentin," Biomaterials, vol. 27, no. 9, pp. 2131-2140, 2006.

[28] G. Plotino, N. M. Grande, R. Bedini, C. H. Pameijer, and F. Somma, "Flexural properties of endodontic posts and human root dentin," Dental Materials, vol. 23, no. 9, pp. 1129-1135, 2007.

[29] C. Schatz, M. Strickstrock, M. Roos et al., "Influence of specimen preparation and test methods on the flexural strength results of monolithic zirconia materials," Materials, vol. 9, no. 3, p. 180, 2016

[30] R. Bohner, M. Claude, and C. Kopfmann, "Characteristics of polymer based CAD/CAM blocks for permanent restorations," in Proceedings of the 2015 Continental European and Scandinavian Divisions Meeting, Antalya, Turkey, October 2015, https://iadr.abstractarchives.com/abstract/ ced-iadr2015-2299825/characteristics-of-polymer-based-cadcamblocks-for-permanent-restorations.

[31] A. Goujat, H. Abouelleil, P. Colon et al., "Mechanical properties and internal fit of 4 CAD-CAM block materials," The Journal of Prosthetic Dentistry, vol. 119, no. 3, pp. 384389, 2018.

[32] N. C. Lawson, R. Bansal, and J. O. Burgess, "Wear, strength, modulus and hardness of CAD/CAM restorative materials," Dental Materials, vol. 32, no. 11, pp. e275-e283, 2016.

[33] M. Shafter, V. Jain, R. Wicks, and D. Nathanson, "Effect of thermocycling on flexural strength of different CAD/CAM material," Journal of Dentistry \& Oral Disorders, vol. 3, no. 5, p. 1071, 2017.

[34] B. Stawarczyk, A. Liebermann, M. Eichberger, and J.-F. Güth, "Evaluation of mechanical and optical behavior of current esthetic dental restorative CAD/CAM composites," Journal of the Mechanical Behavior of Biomedical Materials, vol. 55, pp. 1-11, 2016.
[35] S. F. Ang, T. Scholz, A. Klocke, and G. A. Schneider, "Determination of the elastic/plastic transition of human enamel by nanoindentation," Dental Materials, vol. 25, no. 11, pp. 1403-1410, 2009.

[36] L. H. He, N. Fujisawa, and M. V. Swain, "Elastic modulus and stress-strain response of human enamel by nano-indentation," Biomaterials, vol. 27, no. 24, pp. 4388-4398, 2006.

[37] E. D. Yilmaz, H. Jelitto, and G. A. Schneider, "Uniaxial compressive behavior of micro-pillars of dental enamel characterized in multiple directions," Acta Biomaterialia, vol. 16, pp. 187-195, 2015.

[38] J. H. Kinney, M. Balooch, S. J. Marshall, G. W. Marshall Jr., and T. P. Weihs, "Hardness and young's modulus of human peritubular and intertubular dentine," Archives of Oral Biology, vol. 41, no. 1, pp. 9-13, 1996.

[39] W. Grzebieluch, B. Romuald, C. Tomasz, and U. Kaczmarek, "The mechanical properties of human dentin for 3-D finite element modeling-numerical and analytical evaluation," Advances in Clinical and Experimental Medicine, vol. 26, no. 4, pp. 645-653, 2017.

[40] R. Argyrou, G. A. Thompson, S.-H. Cho, and D. W. Berzins, "Edge chipping resistance and flexural strength of polymer infiltrated ceramic network and resin nanoceramic restorative materials," The Journal of Prosthetic Dentistry, vol. 116, no. 3, pp. 397-403, 2016.

[41] A. Della Bona, P. H. Corazza, and Y. Zhang, "Characterization of a polymer-infiltrated ceramic-network material," Dental Materials, vol. 30, no. 5, pp. 564-569, 2014.

[42] A. Albero, A. Pascual, I. Camps, and M. Grau-Benitez, "Comparative characterization of a novel cad-cam polymer-infiltrated-ceramic-network," Journal of Clinical and Experimental Dentistry, vol. 7, no. 4, pp. e495-e500, 2015.

[43] K. C. Yamanel, A. Çaglar, K. Gülsahi, and U. A. Özden, "Effects of different ceramic and composite materials on stress distribution in inlay and onlay cavities: 3-D finite element analysis," Dental Materials Journal, vol. 28, no. 6, pp. 661-670, 2009.

[44] K. J. Donly, M. E. Jensen, P. Triolo, and D. Chan, “A clinical comparison of resin composite inlay and onlay posterior restorations and cast-gold restorations at 7 years," Quintessence International (Berlin, Germany: 1985), vol. 30, no. 3, pp. 163-168, 1999.

[45] M. N. Mandikos, G. P. McGivney, E. Davis, P. J. Bush, and J. M. Carter, "A comparison of the wear resistance and hardness of indirect composite resins," The Journal of Prosthetic Dentistry, vol. 85, no. 4, pp. 386-395, 2001.

[46] P. Kamonwanon, N. Hirose, S. Yamaguchi et al., " $\mathrm{SiO}_{2}$ nanocomposite film coating of CAD/CAM composite resin blocks improves surface hardness and reduces susceptibility to bacterial adhesion," Dental Material Journal, vol. 36, no. 1, pp. 88-94, 2017.

[47] M. D. P. Gutiérrez-Salazar and J. Reyes-Gasga, "Microhardness and chemical composition of human tooth," Materials Research, vol. 6, no. 3, pp. 367-373, 2003.

[48] L. Cao, X. Zhao, X. Gong, and S. Zhao, "An in vitro investigation of wear resistance and hardness of composite resins," International Journal of Clinical and Experimental Medicine, vol. 6, no. 6, pp. 423-430, 2013.

[49] A. Tsujimoto, W. W. Barkmeier, N. G. Fischer et al., "Wear of resin composites: current insights into underlying mechanisms, evaluation methods and influential factors," Japanese Dental Science Review, vol. 54, no. 2, pp. 76-87, 2018.

[50] A. D. Bona, K. J. Anusavice, and P. H. DeHoff, "Weibull analysis and flexural strength of hot-pressed core and 
veneered ceramic structures," Dental Materials: Official Publication of the Academy of Dental Materials, vol. 19, no. 7, pp. 662-669, 2003.

[51] J. B. Quinn and G. D. Quinn, "A practical and systematic review of Weibull statistics for reporting strengths of dental materials," Dental Materials, vol. 26, no. 2, pp. 135-147, 2010.

[52] S. A. Rodrigies Jr, J. L. Ferracane, and A. Della Bona, "Flexural strength and Weibull analysis of a microhybrid and a nanofill composite evaluated by 3-and 4-point bending tests," Dent Mater, vol. 24, pp. 426-431, 2008.

[53] J. F. McCabe and T. E. Carrick, "A statistical approach to the mechanical testing of dental materials," Dental Materials, vol. 2, no. 4, pp. 139-142, 1986.

[54] E. G. Mota, L. N. Smidt, L. M. Fracasso, L. H. Burnett, and A. M. Spohr, "The effect of milling and postmilling procedures on the surface roughness of CAD/CAM materials," Journal of Esthetic and Restorative Dentistry, vol. 29, no. 6, pp. 450-458, 2017. 